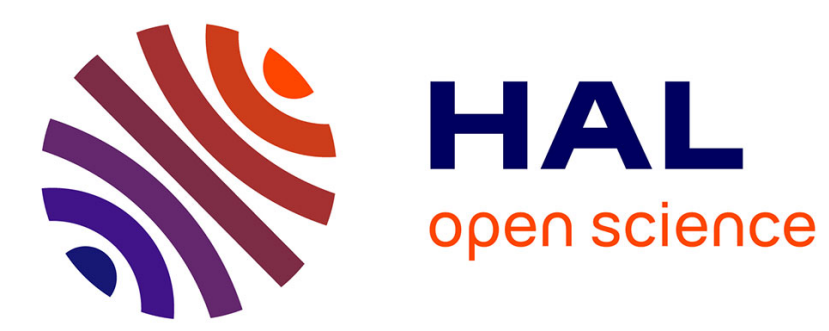

\title{
NEEDS FOR HIGH RESOLUTION SPECTROSCOPY IN ULTRAVIOLET SOLAR PHYSICS
}

\author{
Patrick Lemaire
}

\section{To cite this version:}

Patrick Lemaire. NEEDS FOR HIGH RESOLUTION SPECTROSCOPY IN ULTRAVIOLET SOLAR PHYSICS. Journal de Physique Colloques, 1988, 49 (C1), pp.C1-335-C1-337. 10.1051/jphyscol:1988172 . jpa-00227586

\section{HAL Id: jpa-00227586 https://hal.science/jpa-00227586}

Submitted on 1 Jan 1988

HAL is a multi-disciplinary open access archive for the deposit and dissemination of scientific research documents, whether they are published or not. The documents may come from teaching and research institutions in France or abroad, or from public or private research centers.
L'archive ouverte pluridisciplinaire HAL, est destinée au dépôt et à la diffusion de documents scientifiques de niveau recherche, publiés ou non, émanant des établissements d'enseignement et de recherche français ou étrangers, des laboratoires publics ou privés. 
JOURNAL DE PHYSIOUE

Colloque C1, Supplément au $n^{\circ} 3$, Tome 49, Mars 1988

C1-335

\title{
NEEDS FOR HIGH RESOLUTION SPECTROSCOPY IN ULTRAVIOLET SOLAR PHYSICS
}

\author{
P. LEMAIRE
}

LPSP, BP 10, F-91371 Verrières-1e-Buisson Cedex, France

Résumé : L'étude des couches extérieures de l'atmosphère solaire (de $5000^{\circ} \mathrm{K}$ à quelques $10^{\circ}{ }^{\circ} \mathrm{K}$ ) s'effectue à l'aide des raies ultraviolettes émises par des éléments plusieurs fois ionisés. La résolution des structures fines solaires a été faite avec une bonne résolution spectrale par quelques expériences (OSO 8 , SMM, HRTS) au dessus de $100 \mathrm{~nm}$. L'établissement du bilan global et détaillé de l'atmosphère est nécessaire pour essayer de comprendre les processus de chaufage, la génération du vent solaire et ses mécanismes d'accélération. Les nouveaux spectromètres ultraviolets proposés sur le satellite soHO doivent permettre de combiner les résolutions angulaires, spectrales et temporelles suffisantes pour répondre à ce besoin.

\begin{abstract}
The study of the solar atmosphere (from $5000^{\circ} \mathrm{K}$ to few millions $K$ ) is made through ultraviolet lines emitted by ionized elements. Some experiments (OSO 8, SMM, HRTS), observing above $100 \mathrm{~nm}$ have resolved the fine solar structure with a good spectral resolution. The understanding of the heating processes, the solar wind generation and its acceleration mechanisms require a global and detailed mass and energy budget of the atmosphere. The new ultraviolet spectrometers proposed on soHO satellite are able to combine enough angular, spectral and temporal resolutions to establish this budget.
\end{abstract}

\section{Introduction}

The solar atmosphere is highly structured with flux tubes (photosphere and Iow chromosphere) and loops (upper chromosphere and corona) embedded in a wide background atmosphere. From the ultraviolet and extreme ultraviolet observations (below $200 \mathrm{~nm}$ down to $10 \mathrm{~nm}$ ) a lot of lines emitted by several times ionized species give access to atmospheric parameters in the $5000^{\circ} \mathrm{K}$. With such lines the chromosphere to corona characteristics can be defined. The importance of high resolution observations in this spectral range has been already emphasized by Brueckner [1].

\section{A Structure Solar Atmosphere}

Although the structuration of the solar atmosphere has been known from the ground (eclipse observations) and from space (from rocket flights and OSO series) the ATM/SKYLAB observations, by their quality and the large community involved in their acquisition, reduction and interpretation have produced a significant progress in our knowledge. From these data we know that the upper solar atmosphere is build by loops (cool or hot) whose lengths range from $10^{4} \mathrm{~km}$ up to $7.10^{5} \mathrm{~km}$ ( 30 arcseconds up to 16 arcmin) and diameters varie from about $1000 \mathrm{~km}$ ( 1.5 arcsec) to $10000 \mathrm{~km}$ ( 15 arcsec) and some cool loops ( $\approx 10^{5} \cdot \mathrm{K}$ ) may be overlying hot loops $\left(\approx 10^{6} \cdot K\right)$. High resolution HILy pictures obtained during rocket flights (Bonnet et al., [2]) show that at the one arcsecond resolution there is a fibril structure of that will appear homogeneous with low resolution observation, and, probably there is still unresolved features.

High Resolution Telescope and Spectrograph rocket flights (HRTS, [3], [4]) have determined some line profile characteristics above $117 \mathrm{~nm}$. The doppler shift of lines in small area (down to one arcsecond) varies from few kilometers per second to more than $400 \mathrm{kms}^{-1}$ in ejecta events with about 60 seconds lifetime. 


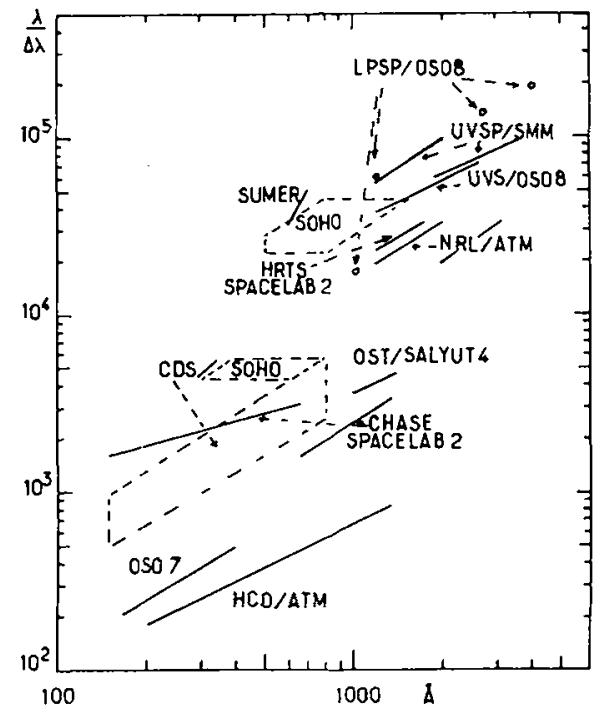

Figure la Performances of previous in-orbit experiments and proposed new instrumentations The resolving power $\lambda / \Delta \lambda$ is given as a function of the wavelength

OSO $7 /$ GSFC (1974; [6])

HCO/ATM (SO55, 1973-74; [ rj)

NRL/ATM (SO82B , I973-74; [8])

OST/SALYUT 4 (1975; [9])

LPSP/OSO $8(1975-78 ;$ [10])

UVS/OSO $8(1975-78 ;[11])$

UVSP/SMM (1980-87; [12] )

HRTS/SPACELAB 2 (1985; [13])

CHASE/SPACELAB 2 (1985; [14])

CDS/SOHO (Patchett B., 1987, Private communication)

SUMBR/SOHO (Wilhelm K., 1987, Private communication)

\section{Resolution Required to Obtain Inproved Diagnostics}

It is clearly evident that to improve densities and temperatures values deduced from line ratio techniques or from emission measures (such as derived by Doyle et al. [5]) an angular resolution better than the 25 arcsec ${ }^{2}$ obtained by HCO/ATM experiment in the 30-130 nm wavelength range is needed to separate the contribution of several loops or different parts of the loop. An improved throughput is gained by a simultaneous collecting of several angular pixels along the entrance slit of a stigmatic spectrometer.

Identification of line shape to deduce line profile deformations and shifts is required to measure flow velocities, turbulence or impulsive events. Line shape may be detected with few pixels in the profiles and the line center position with good statistic may be estimate to about one tenth of the spectral resolution element. A detection of $1 \mathrm{~km} / \mathrm{sec}$ doppler shift may be performed with a $3.10^{4}$ resolving power.

Two new instrumentations, CDS and SUMER, have been proposed for the sOHO (Solar and Heliospheric observatory-ESA) payload. The first one is mainly dedicated to line pair ratios and emission measure techniques in short wavelength domain $(15-80 \mathrm{~nm})$ and the second one is optimized to line profile measurements in the 50-160 nm wavelength range. These two complementary instruments use stigmatic spectrometers with two dimensional detector arrays. The performances are given in 
figure la and $b$. They represent a real gap above those obtained by previous satellite experiments (Spacelab 2 experiments had only a week of observations in the cargo bay of the space shuttle).

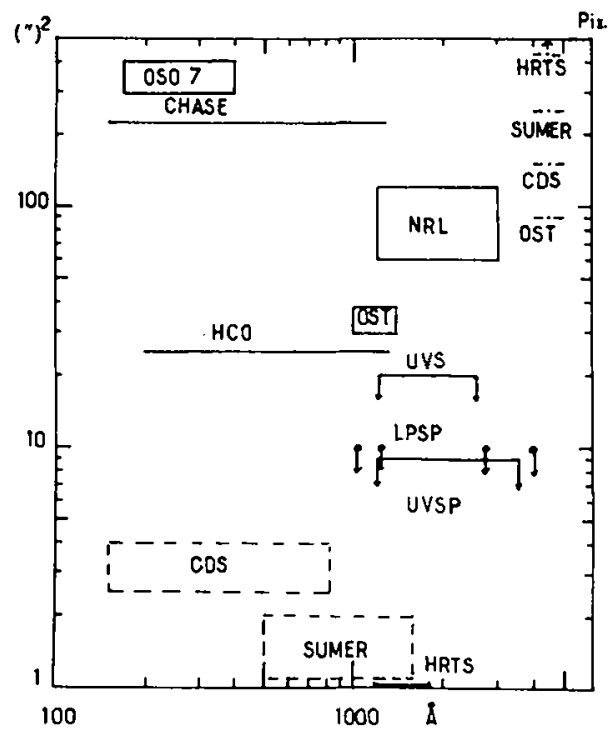

Figure lb Performances of previous in-orbit experiments and proposed new instrumentations

The angular resolution is given by the entrance slot pixel (squared arcsecond, left ordinate) as a function of wavelength and angular pixel number (right ordinate). Experiments are identified as in Figure la. For oso 8 and SMM instrumentations the resolution corresponds to the most used entrance slits. Instrumentations listed on the right column have simultaneous angular pixels, all other space experiments have only one entrance angular pixel at a $t$ ime.

\section{References}

[1] Brueckner G.E., Applied Opt. 19 (1980) 3994

[2] Bonnet R.M., Bruner B.C., Acton L.W., Brown W.A., Decaudin M., Astrophys. J. 237 (1980) L47

[3] Dere K.P., Solar Phys. 77 (1982) 77

14] Dere K.P., Bartoe J-D.F., Brueckner G.E., Astrophys. J. 305 (1986) 947

[5] Doyle J.G., Mason H.E., Vernazza J.E., Astron. Astrophys. 150 (1985) 69

[6] Underwood J.H., Neupert W.M., Solar Phys. 35 (1974) 241

[7] Reeves B.M., Huber M.C.E., Timothy J.G., Appl. Opt. 16 (1977) 837

[8] Bartoe J-D.F., Brueckner G.E., Purcell J.D., Tousey R., Appl. Opt. 16 (1977) 879

[9] Bruns A.V., Grechko G.M., Gubarjev A.A., Severny A.B., Steshenko N.V., Space Res. XVI (1976) 813

[10] Bonnet R.M., Lemaire P., Vial J-C., Artzner G., Gouttebroze P., Jouchoux A., Leibacher J., Skumanich A., Vidal Majar A., Astrophys. J. 221 (1978) 1032

[11] Bruner B.C., Space Sci. Instrument. 3 (1977) 369

[12] Miller M.S., Caruso A.J., Hoodgate B.E., Sterk A.A., Appl. Opt. 20 (1981) 3805

[13] Brueckner G.E., Bartoe J-D.F., VanHoosier M.E., Proc. of the OSO 8 Workshop, LASP, University of Colorado-Boulder, E. Hansen ed. (1977) 380

[14] Patchett B.E., Norman K., Gabriel A.H., Culhane J.L., Space Sci. Rev. 29 (1981) 431 